\title{
Photostability of Loratadine Inclusion Complexes with Natural Cyclodextrins
}

\author{
Patricia Elizabeth Rivas-Granizo, Leandro Giorgetti, and Humberto Gomes Ferraz \\ Department of Pharmacy, Faculty of Pharmaceutical Sciences, University of São Paulo, Rua do Lago 250, Prédio Semi-Industrial, \\ Cidade Universitária, Butantã, 05508-080 São Paulo, SP, Brazil \\ Correspondence should be addressed to Humberto Gomes Ferraz; sferraz@usp.br
}

Received 20 October 2015; Accepted 10 December 2015

Academic Editor: Iqbal Ahmad

Copyright (C) 2015 Patricia Elizabeth Rivas-Granizo et al. This is an open access article distributed under the Creative Commons Attribution License, which permits unrestricted use, distribution, and reproduction in any medium, provided the original work is properly cited.

\begin{abstract}
The purpose of this study was to evaluate the photostability of inclusion complexes of the histamine antagonist loratadine (LORA) with $\alpha$-, $\beta$-, and $\gamma$-cyclodextrins (CDs). Accordingly, binary drug-CD complexes were prepared using the coevaporation method at $1: 1,1: 2$, and $1: 3$ stoichiometric ratios, which were characterized by thermal analysis. Subsequently, solutions of the complexes at $500 \mu \mathrm{g} \mathrm{mL} \mathrm{m}^{-1}$ in $\mathrm{HCl} 0.1 \mathrm{M}$ were subjected to irradiation in a photostability chamber for 12 hours, and the content of the remaining active ingredient was quantified by means of high-performance liquid chromatography. It is possible to observe the presence of two products originating from photodegradation (P1 and P2), which were identified in solutions of loratadine with $\alpha$ - and $\beta$-CD. By means of statistical analysis, we conclude that the drug: $\alpha$-CD and drug: $\gamma$-CD $(1: 1)$ complexes proved to be more efficient in the photostability assay, obtaining a nonsignificant level of degradation and full recovery of LORA.
\end{abstract}

\section{Introduction}

Photodegradation, in the context of pharmaceutical sciences, is used to describe how a drug compound responds to light exposure, including not only the effect of degradation or breakdown of the molecule, but also processes as oxidation, for example. This phenomenon can lead to a loss of therapeutic power of the active substance or even to the appearance of toxic molecules. Since hundreds of drugs are susceptible to light degradation, it is necessary to find mechanisms during the development phase of the formulation in which irradiation does not interfere with the stability of the molecule [1].

Among the photoprotection strategies available for active substances, the formulation of drug-cyclodextrin inclusion complexes has proven to be a very promising alternative [24]. Cyclodextrins (CD) are oligosaccharides derived from starch, comprising units of $\alpha$-D-glucopyranose joined by $\alpha$, 1-4 bonds, with a structure similar to a truncated cone. Inside this structure, the cavity interacts with the drug, thus forming a protective barrier against external factors, such as light [5]. Due to their low toxicity, availability, and accessible costs, cyclodextrins are being used more and more frequently, especially in drug photoprotection studies. Several studies have shown a significant reduction in photodegradation in inclusion complexes of cyclodextrins containing methotrexate [3], quercetin [4], isradipine [6], ibuprofen [7], and some dihydropyridines $[8,9]$.

Loratadine (LORA) is a second-generation benzene cycloheptane antihistamine, used for the treatment of skin and eye allergies, as well as rhinitis [10-13]. It is presented as a white powder, poorly soluble in water, but soluble in $\mathrm{HCl}$ $0.1 \mathrm{M}$. Its formula is $\mathrm{C}_{22} \mathrm{H}_{23} \mathrm{CIN}_{2} \mathrm{O}_{2}$ and its molecular weight is $382.8 \mathrm{~g} \mathrm{~mol}^{-1}$. It is usually sold in the form of tablets and syrups. The chemical structure of LORA (Figure 1) presents organic groups which when exposed to ultraviolet light tends to cause $\pi-\pi^{*}$ and $n-\pi^{*}$ transitions, which result in a breakdown of chemical bonds, creating photodegradation products [1].

The formation of inclusion complexes of LORA with CDs and an assessment of their structure and effect on the increase in solubility of the drug have already been the focus of studies. Among the studies researched, LORA presented satisfactory complexation with natural $\alpha$-, $\beta$-, and $\gamma$-cyclodextrins $[14,15]$, hydroxypropyl- $\beta-\mathrm{CD}$ [14-17], and dimethyl- $\beta-\mathrm{CD}$ 


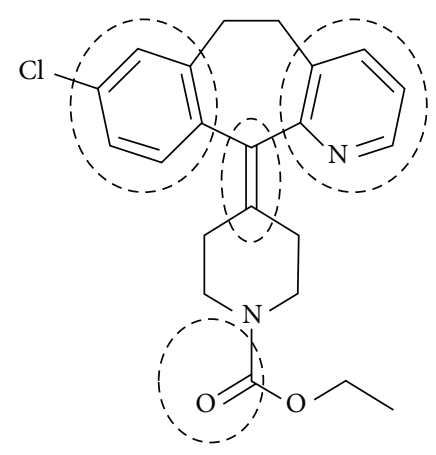

Figure 1: Chemical structure of loratadine. The chemical groups susceptible to light degradation are indicated.

$[18,19]$. These inclusion complexes were obtained by means of coevaporation techniques, freeze-drying, and others.

However, it is interesting to note that no scientific studies were found in literature in which the photostability of LORA was evaluated in the presence of CDs. Accordingly, there is no knowledge of the possibility of using these as agents for protecting the drug from light.

Thus, the objective of this study was to evaluate the impact of complexation of LORA with natural CDs, more specifically $\alpha$-cyclodextrin $(\alpha-\mathrm{CD}), \beta$-cyclodextrin $(\beta$-CD), and $\gamma$-cyclodextrin $(\gamma$-CD) on the photostability of the drug.

\section{Material and Methods}

2.1. Reagents. Loratadine (Chemo Lugano Branch, Switzerland), HPLC grade acetonitrile, potassium phosphate monobasic $\left(\mathrm{KH}_{2} \mathrm{PO}_{4}\right)$ and ethanol (Merck, Germany), and deionized water were used.

2.2. Preparation of the LORA Sample Solution. The LORA sample solution $\left(500 \mu \mathrm{g} \mathrm{mL}^{-1}\right)$ was prepared by transferring $25 \mathrm{~mL}$ from a $1 \mathrm{mg} \mathrm{mL}^{-1}$ stock solution to a $50 \mathrm{~mL}$ volumetric flask, topped up with $\mathrm{HCl} 0.1 \mathrm{M}$. The solution was homogenized and an aliquot was filtered through a $0.45 \mu \mathrm{m}$ Millex membrane, with a prior discard of $2 \mathrm{~mL}$, in order to saturate the filter.

2.3. Obtaining Cyclodextrin Complexes. The cyclodextrins evaluated in this study were $\alpha, \beta$, and $\gamma$, all provided by Wacker Chemie, Germany. The complexation procedure comprised preparation of LORA solutions in ethanol (10 mL) and of each of the CDs in water, which were mixed at a ratio of $1: 1,1: 2$, and $1: 3$ and maintained under magnetic shaking at $500 \mathrm{rpm}$ for 48 hours. The complexes were obtained by means of rotaevaporation in a TE 210 apparatus (Tecnal, Brazil) and subsequent drying in a forced-air oven (Fabber-Primar, Brazil).

2.4. Thermal Analysis. For physicochemical characterization of the complexes obtained, differential scanning calorimetry (DSC) and thermogravimetry (TG) were used. DSC analyses were conducted using a DSC 2920 (TA Instruments, New Castel, USA) apparatus and a hermetically sealed crucible containing about $2 \mathrm{mg}$ of sample, which was submitted to heating at a range of $25^{\circ} \mathrm{C}$ to $300^{\circ} \mathrm{C}$, under a dynamic $\mathrm{N}_{2}$ atmosphere, with a flow of $50 \mathrm{~mL} \cdot \mathrm{min}^{-1}$ and a heating rate of $10^{\circ} \mathrm{C} \mathrm{min}^{-1}$.

The TG curves were obtained using a TGA 2950 (TA Instruments, New Castel, USA) apparatus and a platinum crucible with approximately $10 \mathrm{mg}$ of sample submitted to a heating range of $25^{\circ} \mathrm{C}$ to $500^{\circ} \mathrm{C}$, under a dynamic $\mathrm{N}_{2}$ atmosphere, with a flow of $100 \mathrm{~mL} \cdot \mathrm{min}^{-1}$ and a heating rate of $10^{\circ} \mathrm{C} \mathrm{min}^{-1}$. For improved comprehension of the weight loss phenomenon, the derivative (DTG) of each curve obtained was calculated.

2.5. Photostability of the Complexes. In order to evaluate photostability, drug complex-CD solutions were prepared at $500 \mu \mathrm{g} \mathrm{mL}^{-1}$, previously filtered through a $0.45 \mu \mathrm{m}$ membrane. The solutions were placed in quartz cuvettes, with a $1 \mathrm{~cm}$ optic pathway. Furthermore, control samples were prepared, which were fully wrapped in tin foil. All the containers were exposed to light in a FARMA 424 photostability chamber (Nova Ética, Brazil), under a controlled temperature of $25^{\circ} \mathrm{C} \pm 0.5$ for 12 hours. The light sources in the chamber correspond to option 2 of the Q1B guide issued by the International Conference on Harmonisation [20] and they were adequately calibrated and qualified. After irradiation, the remaining LORA content was evaluated using a chromatographic method.

2.6. Chromatographic Conditions. The remaining drug content was quantified using a high-performance liquid chromatography (HPLC) method, previously developed and validated for linearity and precision. The assays were conducted with a LaChrom Elite chromatograph (Hitachi, Tokyo, Japan), consisting of a L-2130 pump, L-2200 automatic sampler, L-2300 oven, and a diode-array detector (DAD) L2455.

The chromatograph method was developed for loratadine in the presence of cyclodextrins, from a Lichrospher $100 \mathrm{RP}-$ $18,4.6 \times 250 \mathrm{~mm}$ column, and $5 \mu \mathrm{m}$ particle (Merck, Germany), maintained at $25^{\circ} \mathrm{C}$ in a mobile phase, comprising acetonitrile and ammonium acetate $0.01 \mathrm{M}$ under a flow of $1.5 \mathrm{~mL} \cdot \mathrm{min}^{-1}$. Elution followed $30: 70(0-5 \mathrm{~min}), 40: 60$ (5$10 \mathrm{~min}), 50: 50(10-25 \mathrm{~min})$, and $30: 70$ (25-30 min) gradients. The injection volume used was $10 \mu \mathrm{L}$, and the wavelength was adjusted to $235 \mathrm{~nm}$. The chromatograms (and their respective data) were generated using the EZChrom Elite 3.1.7 software program (Agilent Technologies, Santa Clara, USA).

2.7. Statistical Evaluation of the Results. In order to statistically evaluate the efficiency of LORA complexation with cyclodextrins and its impact on the photosensitivity of the drug, the type of $\mathrm{CD}$ used $(\alpha, \beta$, or $\gamma)$ and the ratio $(1: 1,1: 2$, or $1: 3)$ were defined as independent variables within an experimental design of the factorial $3^{2}$ type, which considered loss of mass of the binary complex of the drug after the photosensitivity assay. The results in the form of variance analysis and surface response were obtained using the Statistica 12.7 software program. 


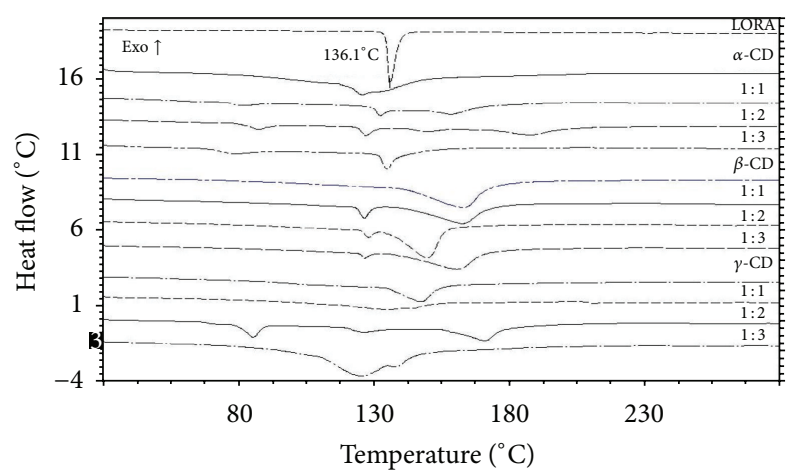

Figure 2: DSC curves of LORA, CDs, and LORA: $\alpha$-CD, LORA: $\beta$ CD, and LORA: $\gamma$-CD complexes (ratios $1: 1,1: 2$, and $1: 3$ ), obtained under a dynamic $\mathrm{N}_{2}\left(50 \mathrm{~mL} \cdot \mathrm{min}^{-1}\right)$ atmosphere and a heating rate of $10^{\circ} \mathrm{C} \mathrm{min}-1$

TABLE 1: Loss of mass obtained by DTG (TG derivative) of LORA, of the $\alpha$-CD, $\beta$-CD, and $\gamma$-CD complexes (ratios $1: 1,1: 2$, and $1: 3$ ).

\begin{tabular}{lcc}
\hline Sample & Loss of mass I \% $\left({ }^{\circ} \mathrm{C}\right)$ & Loss of mass II \% $\left({ }^{\circ} \mathrm{C}\right)$ \\
\hline LORA & - & $99.94(322.68)$ \\
$\alpha$-CD & $9.04(84.49)$ & $77.37(325.83)$ \\
Ratio $1: 1$ & $6.61(84.43)$ & $64.14(336.84)$ \\
Ratio $1: 2$ & $7.06(84.00)$ & $64.23(337.63)$ \\
Ratio $1: 3$ & $7.34(84.86)$ & $68.27(336.30)$ \\
$\beta$-CD & $13.83(89.04)$ & $73.02(335.68)$ \\
Ratio $1: 1$ & $9.84(77.64)$ & $66.35(353.52)$ \\
Ratio $1: 2$ & $10.11(73.90)$ & $72.24(349.45)$ \\
Ratio $1: 3$ & $11.07(79.53)$ & $70.99(342.38)$ \\
$\gamma$-CD & $8.85(76.54)$ & $77.22(346.61)$ \\
Ratio $1: 1$ & $12.13(51.57)$ & $64.71(346.18)$ \\
Ratio $1: 2$ & $10.60(65.22)$ & $71.33(357.42)$ \\
Ratio $1: 3$ & $12.65(66.86)$ & $73.15(342.11)$ \\
\hline
\end{tabular}

\section{Results and Discussion}

3.1. Evaluation of the Formation of Drug-CD Complexes. Figure 2 presents the DSC curves of the LORA: $\alpha-C D$, LORA: $\beta$-CD, and LORA: $\gamma$-CD complexes in the three ratios tested. The isolated drug presented a characteristic endothermic event, corresponding to a melting peak at $136.01^{\circ} \mathrm{C}$. When compared to the complexes with $\alpha$-CD in the $1: 1$ and $1: 2$ ratios, significant shifts were observed in the melting peak, from $127.23^{\circ} \mathrm{C}$ to $132.45^{\circ} \mathrm{C}$, respectively. This fact is evidence of the inclusion of the drug within the CD cavity. However, at the ratio of $1: 3$ there is no considerable shift in the drug peak, which appears at $135.0^{\circ} \mathrm{C}$. Several other characteristic events of $\alpha$-CD were observed between $70.67^{\circ} \mathrm{C}$ and $188.15^{\circ} \mathrm{C}$.

Similarly, $\beta$-CD complexes were observed to present modifications in the melting events. However, the presence of characteristic drug peaks shifted to $126.63^{\circ} \mathrm{C}(1: 1), 128.18^{\circ} \mathrm{C}$ $(1: 2)$, and $126.84^{\circ} \mathrm{C}(1: 3)$ and $\beta-\mathrm{CD}$ peaks, shifted to $162.79^{\circ} \mathrm{C}$ $(1: 1), 149.59^{\circ} \mathrm{C}(1: 2)$, and $160.62^{\circ} \mathrm{C},(1: 3)$ were observed. The peak shift, even at a smaller temperature scale, is evidence of possible drug complexation.

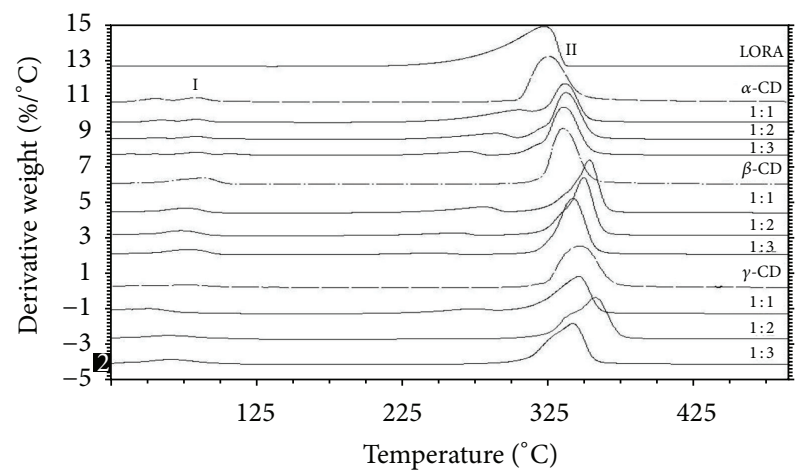

FIGURE 3: DTG curves for LORA, CDs, and LORA: $\alpha$-CD, LORA: $\beta$ CD, and LORA: $\gamma$-CD complexes (ratios $1: 1,1: 2$, and 1:3). Loss of masses (I) and (II), obtained under a dynamic $\mathrm{N}_{2}$ atmosphere

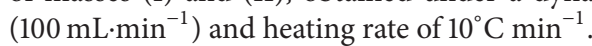

However, for the drug: $\gamma$-CD complexes, it is possible to observe complexation through a shift in the drug peak to $125.89^{\circ} \mathrm{C}(1: 1), 134.87^{\circ} \mathrm{C}(1: 2)$, and $125.31^{\circ} \mathrm{C}(1: 3)$ shown as melting of the $\mathrm{CD}$ and drug events, resulting in wide peaks and complex formation characteristics.

The thermogravimetric curves of the LORA complexes with $\alpha$-CD, $\beta$-CD, and $\gamma$-CD (ratios $1: 1,1: 2$, and $1: 3$ ) presented mass-loss events that were visually perfected with the calculation of the derivative (DTG), as presented in Figure 3. It is possible to note the presence of two events in all the curves, corresponding to loss of water molecules (I) and degradation of the compounds under analysis. The results contained in Table 1 show that the mass loss of event II is reduced in the complexes, compared to that observed for the isolated drug and cyclodextrins.

Finally, the statistical analysis of these results, demonstrated by means of a surface-response graph (Figure 4), indicates that the drug: $\mathrm{CD}$ ratio has a greater impact on complexation than the type of cyclodextrin used. In fact, $1: 1$ samples present less mass loss compared to the $1: 2$ and $1: 3$ ratios, thus suggesting that complexation is better from a mixture of an equivalent amount of loratadine and cyclodextrin.

3.2. Photostability of the Complexes. The chromatographic method used to quantify the drug after the photostability study of the complexes was also validated in the presence of CDs, which led to a change in the retention time of the LORA peak. Even so, the method developed was considered adequate, in accordance with the parameters established in the ICH Q2(R1) guide [21].

The chromatographic analysis of loratadine $500 \mu \mathrm{g} \mathrm{mL}^{-1}$ (Figure 5) shows that after 12 hours of irradiation several photodegradation products form, which are eluded at between 8 and 15 minutes. On the other hand, when the drug is complexed with CDs, these products are not eluded, which suggests that the drug inside the cyclodextrin is protected against luminous irradiation. It is worth emphasizing, however, the detection of two peaks, called P1 and P2, which may be related to photodegradation structures, since they are not eluded in control samples, which were protected 
TABLE 2: Percentage of LORA recovered from binary complexes with $\alpha$-CD, $\beta$-CD, and $\gamma$-CD, obtained by coevaporation, after 12 hours of irradiation in solution. The values correspond to the average of five determinations \pm relative standard deviation $( \pm \mathrm{DPR})$.

\begin{tabular}{lccccccccc}
\hline \multirow{2}{*}{ Complex } & \multicolumn{3}{c}{$\alpha$-CD } & \multicolumn{3}{c}{$\beta$-CD } & \multicolumn{3}{c}{$\gamma$-CD } \\
& LORA & P1 & P2 & LORA & P1 & P2 & LORA & P1 & P2 \\
\hline $1: 1$ & $96.36 \pm 0.06$ & $0.57 \pm 2.95$ & $0.46 \pm 3.22$ & $93.63 \pm 0.15$ & $1.16 \pm 1.36$ & $1.36 \pm 0.44$ & $99.15 \pm 0.04$ & $0.27 \pm 2.83$ & $0.48 \pm 1.84$ \\
$1: 2$ & $94.64 \pm 1.01$ & $0.84 \pm 2.12$ & $0.77 \pm 3.67$ & $92.29 \pm 1.19$ & $1.49 \pm 4.41$ & $2.10 \pm 0.54$ & $96.11 \pm 0.16$ & $0.71 \pm 1.15$ & $0.65 \pm 1.73$ \\
$1: 3$ & $93.86 \pm 0.10$ & $0.99 \pm 2.66$ & $0.92 \pm 1.55$ & $89.80 \pm 0.75$ & $1.18 \pm 3.12$ & $1.66 \pm 1.14$ & $94.29 \pm 0.41$ & $0.81 \pm 4.47$ & $0.71 \pm 3.05$ \\
\hline
\end{tabular}

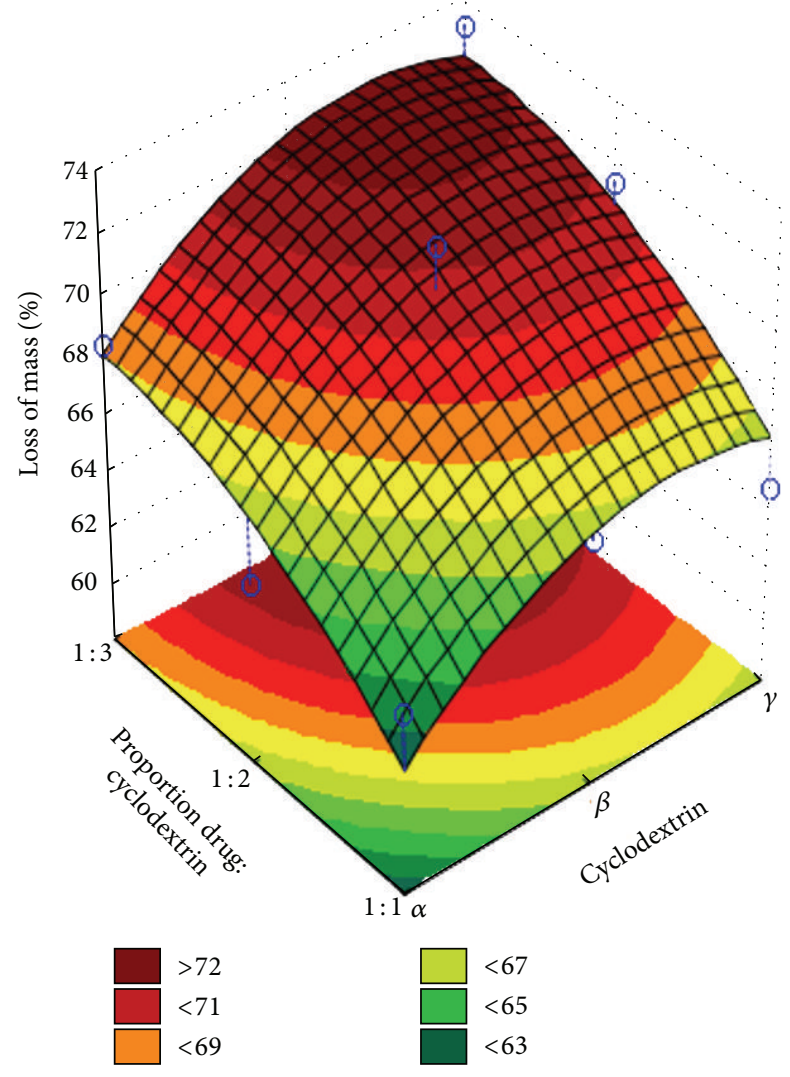

FIGURE 4: The resulting surface-response graph of the statistical analysis of the impact of the drug-CD ratio and the type of $\mathrm{CD}$ on the mass loss in the thermogravimetric assay.

from light. Since the P1 and P2 standards were not available, the degradation of LORA was evaluated by the percentage of remaining drug, compared to the initial concentration $(\mathrm{ICH}, 2006)$. Furthermore, the areas of the P1 and P2 were calculated and compared to the drug peak, according to Table 2.

According to the results presented, the LORA- $\beta-C D$ complex after exposure to light was the one that presented the greatest percentage of recovery of the drug. Similarly, the percentages of $\mathrm{P} 1$ and $\mathrm{P} 2$ proved to be slightly larger compared with the assays executed with other complexes. Compared to other cyclodextrins, this indicates that $\beta-C D$ is not the most adequate for ensuring the photoprotection of LORA in solution, even though it may have presented satisfactory complexation efficiency with the drug.
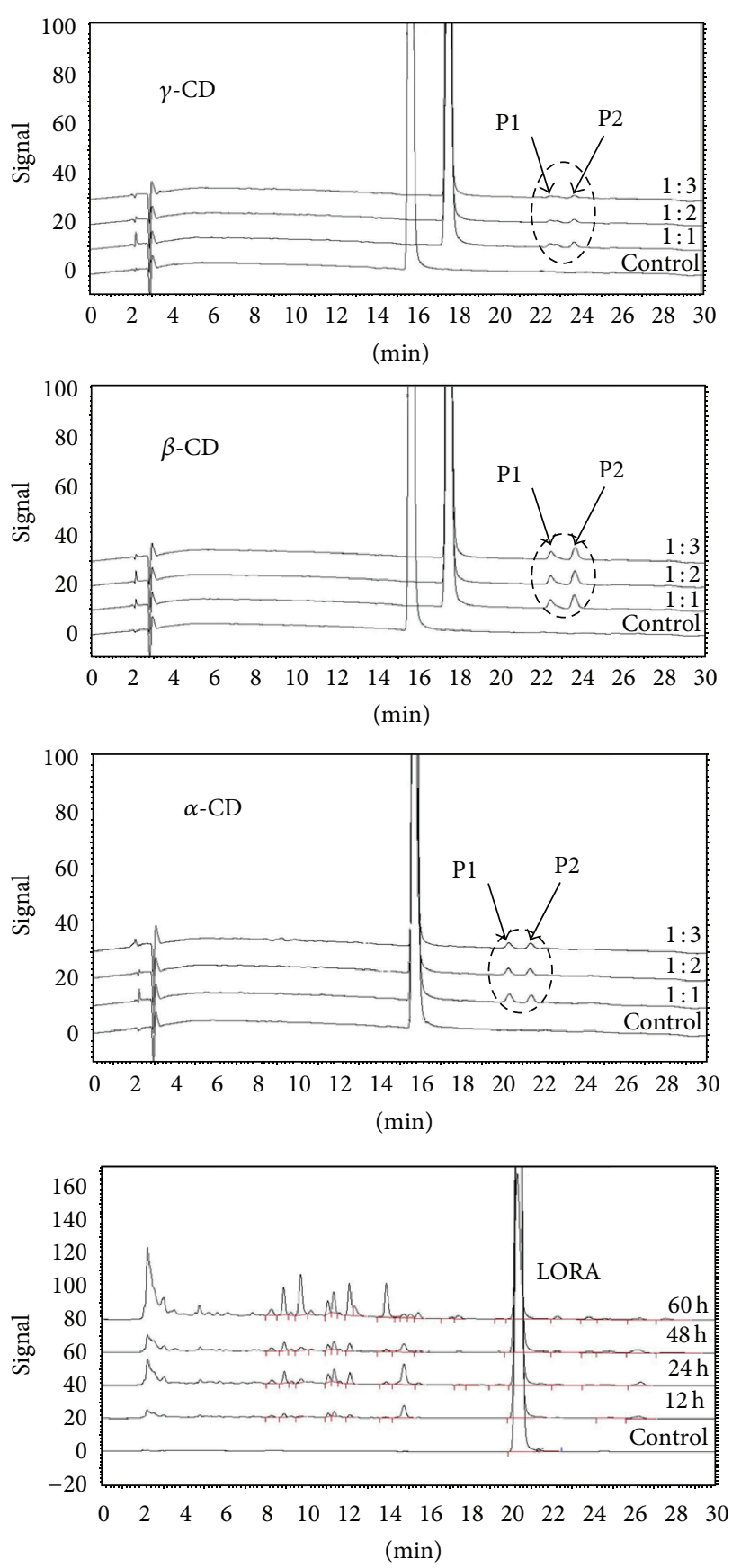

FIGURE 5: LORA chromatograms and complexes with $\alpha$-CD, $\beta$-CD, and $\gamma$-CD, after irradiation. The photodegradation products (P1 and P2) for the binary complexes are highlighted. 


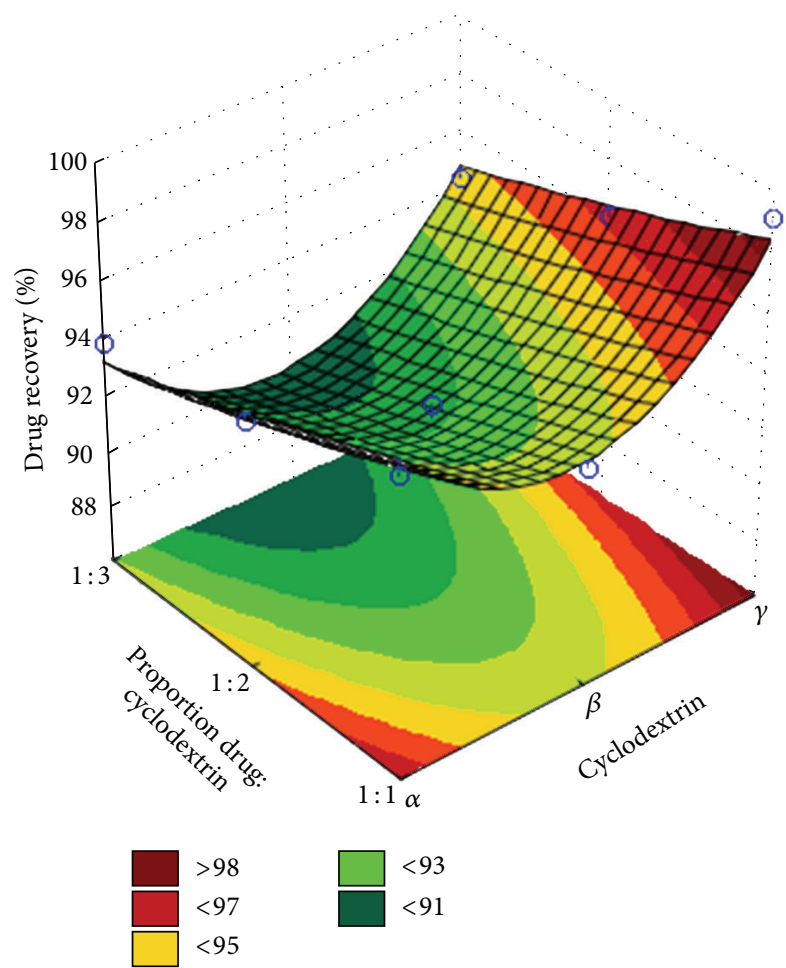

FIGURE 6: The resulting surface-response graph of the statistical analysis of the impact of the drug-CD ratio and the type of $\mathrm{CD}$ on recovery of LORA after photostability assay.

The binary LORA- $\alpha$-CD complexes presented quantities of $\mathrm{P} 1$ and $\mathrm{P} 2$ of less than $1 \%$ and drug recovery reached the maximum value in the $1: 1$ mixture $(96.36 \%)$. The drop in the amount of remaining drug in the $1: 2$ and $1: 3$ mixtures, which is observed in all complexes tested, could be explained by the fact that the excess of cyclodextrins led to an increase of photodegradation of the drug, acting as catalysts in the reaction with regard to luminous radiation [22].

It is also worth emphasizing that the amount of LORA recovered in assays with complexes employing $\gamma$-CD at the ratio of $1: 1$ was $99.15 \%$. Furthermore, it is almost not possible to detect P1 and P2, contrary to what occurs in the analysis of other complexes. This shows that, besides the satisfactory complexation efficiency, already demonstrated in the thermal analysis assays, the $\gamma$-CD acts as an excellent photoprotector agent of the drug in solution, compared to other cyclodextrins tested.

These results were confirmed by statistical analysis, which shows that both the type of CD used and the ratio employed have an impact on the photoprotection of LORA. The surfaceresponse graph (Figure 6) indicates that $\alpha$ - and $\gamma$-CD are in fact better photoprotector agents, especially when complexed with the drug at a ratio of $1: 1$.

Even with small differences found between the complexes, it can be observed that the recovery of loratadine is at least $90 \%$, regardless of the CD and the stoichiometric ratio used. This fact, together with the nondetection of degradation products, shows that the attainment of LORA-CD binary complexes is an interesting strategy for the photoprotection of the drug in solution.

\section{Conclusions}

The use of cyclodextrins has proven to be a very promising resource for the improvement of photostability of LORA. After exposure to light for 12 hours, recovery of the active pharmaceutical ingredient is at least $97 \%$ in the drug: $\alpha-C D$ and drug: $\gamma$-CD complexes at a ratio of $1: 1$, which indicates the photoprotector effect of this excipient.

\section{Conflict of Interests}

The authors declare that there is no conflict of interests regarding the publication of this paper.

\section{Acknowledgments}

The authors would like to thank Coordenação de Aperfeiçoamento de Pessoal de Nível Superior (CAPES) for the grant it provided and Fundação de Amparo à Pesquisa do Estado de São Paulo (FAPESP) for its financial support.

\section{References}

[1] H. H. Tønnesen, "Formulation aproaches for improving solubility and its impact on drug photostability," in Photostability of Drugs and Drug Formulations, H. H. Tønnesen, Ed., pp. 351372, CRC Press, Boca Raton, Fla, USA, 2004.

[2] A. C. Kogawa, A. Zoppi, M. A. Quevedo, H. R. Nunes Salgado, and M. R. Longhi, "Increasing doxycycline hyclate photostability by complexation with $\beta$-cyclodextrin," AAPS PharmSciTech, vol. 15, no. 5, pp. 1209-1217, 2014.

[3] G. Ioele, M. De Luca, L. Tavano, and G. Ragno, “The difficulties for a photolabile drug in topical formulations: the case of diclofenac," International Journal of Pharmaceutics, vol. 465, no. 1-2, pp. 284-290, 2014.

[4] M. Jamrógiewicz, B. Wielgomas, and M. Strankowski, "Evaluation of the photoprotective effect of $\beta$-cyclodextrin on the emission of volatile degradation products of ranitidine," Journal of Pharmaceutical and Biomedical Analysis, vol. 98, pp. 113-119, 2014.

[5] E. M. M. Del Valle, "Cyclodextrins and their uses: a review," Process Biochemistry, vol. 39, no. 9, pp. 1033-1046, 2004.

[6] J. Mielcarek and E. Daczkowska, "Photodegradation of inclusion complexes of isradipine with methyl- $\beta$-cyclodextrin," Journal of Pharmaceutical and Biomedical Analysis, vol. 21, no. 2, pp. 393-398, 1999.

[7] D. A. Godwin, C. J. Wiley, and L. A. Felton, "Using cyclodextrin complexation to enhance secondary photoprotection of topically applied ibuprofen," European Journal of Pharmaceutics and Biopharmaceutics, vol. 62, no. 1, pp. 85-93, 2006.

[8] G. Ioele, M. Luca, and G. Ragno, "Photostability of barnidipine in combined cyclodextrin-in-liposome matrices," Future Medicinal Chemistry, vol. 6, no. 1, pp. 35-43, 2014.

[9] G. Ragno, A. Risoli, G. Loele, E. Cione, and M. De Luca, "Photostabilization of 1,4-dihydropyridine antihypertensives by incorporation into $\beta$-cyclodextrin and liposomes," Journal of 
Nanoscience and Nanotechnology, vol. 6, no. 9-10, pp. 29792985, 2006.

[10] S. P. Clissold, E. M. Sorkin, and K. L. Goa, "Loratadine," Drugs, vol. 37, pp. 42-57, 1989.

[11] K.-G. Wu, T. H. Li, T. Y. Wang, C. L. Hsu, and C. J. Chen, "A comparative study of loratadine syrup and cyproheptadine HCL solution for treating perennial allergic rhinitis in taiwanese children aged 2-12 years," International Journal of Immunopathology and Pharmacology, vol. 25, no. 1, pp. 231-237, 2012.

[12] M. B. Abelson and A. P. Kaplan, "A randomized, doubleblind, placebo-controlled comparison of emedastine 0.05\% Ophthalmic solution with loratadine $10 \mathrm{mg}$ and their combination in the human conjunctival allergen challenge model," Clinical Therapeutics, vol. 24, no. 3, pp. 445-456, 2002.

[13] P. Y. Başak, H. Vural, O. O. Kazanoglu, I. Erturan, and H. I. Buyukbayram, "Effects of loratadine and cetirizine on serum levels of neuropeptides in patients with chronic urticaria," International Journal of Dermatology, vol. 53, no. 12, pp. 15261530, 2014.

[14] L. Omar, M. I. El-Barghouthi, N. A. Masoud et al., "Inclusion complexation of loratadine with natural and modified cyclodextrins: phase solubility and thermodynamic studies," Journal of Solution Chemistry, vol. 36, no. 5, pp. 605-616, 2007.

[15] H.-L. Lin, S.-Y. Lin, C.-C. Lin, C.-H. Hsu, T.-K. Wu, and Y.T. Huang, "Mechanical grinding effect on thermodynamics and inclusion efficiency of loratadine-cyclodextrin inclusion complex formation," Carbohydrate Polymers, vol. 87, no. 1, pp. 512-517, 2012.

[16] S. Pooja, B. Meenakshi, and S. Shruti, "Physicochemical characterization and dissolution enhancement of loratadineHydroxypropyl- $\beta$-cyclodextrin binary systems," Journal of Pharmaceutical Sciences and Research, vol. 3, no. 4, pp. 11701175, 2011.

[17] S.-Y. Lin, C.-H. Hsu, and M.-T. Sheu, "Curve-fitting FTIR studies of loratadine/hydroxypropyl- $\beta$-cyclodextrin inclusion complex induced by co-grinding process," Journal of Pharmaceutical and Biomedical Analysis, vol. 53, no. 3, pp. 799-803, 2010.

[18] A. Szabados-Nacsa, P. Sipos, T. Martinek et al., "Physicochemical characterization and in vitro/in vivo evaluation of loratadine:dimethyl- $\beta$-cyclodextrin inclusion complexes," Journal of Pharmaceutical and Biomedical Analysis, vol. 55, no. 2, pp. 294-300, 2011.

[19] Á. Nacsa, O. Berkesi, P. Szabó-Révész, and Z. Aigner, "Achievement of $\mathrm{pH}$-independence of poorly-soluble, ionizable loratadine by inclusion complex formation with dimethyl- $\beta$ cyclodextrin," Journal of Inclusion Phenomena and Macrocyclic Chemistry, vol. 64, no. 3-4, pp. 249-254, 2009.

[20] Iternational Conference on Harmonisation of Technical Requirements for Registration of Pharmaceuticals for Human Use, Q1B Stability Testing: Photostability Testing of New Drug Substances and Products, 1996.

[21] Iternational Conference on Harmonisation of Technical Requirements for Registration of Pharmaceuticals for Human Use, "Guideline Q2(R1): Validation of Analytical Procedures: Text and Methodology," 2005.

[22] S. Sortino, S. Giuffrida, G. De Guidi et al., "The photochemistry of flutamide and its inclusion complex with $\beta$-cyclodextrin. Dramatic effect of the microenvironment on the nature and on the efficiency of the photodegradation pathways," Photochemistry and Photobiology, vol. 73, no. 1, pp. 6-13, 2001. 

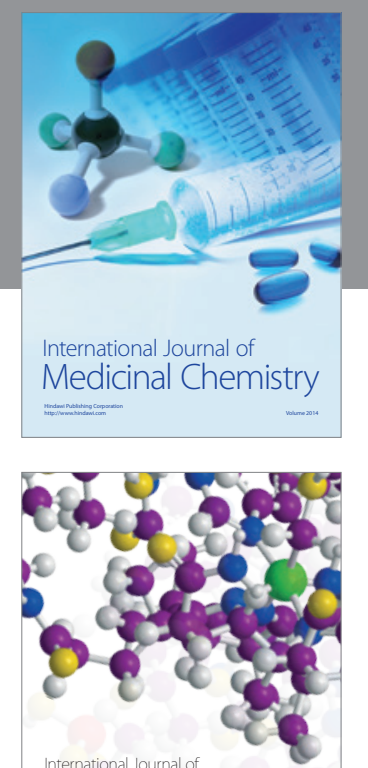

\section{Carbohydrate} Chemistry

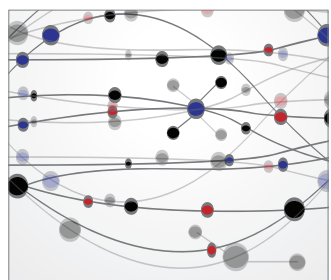

The Scientific World Journal
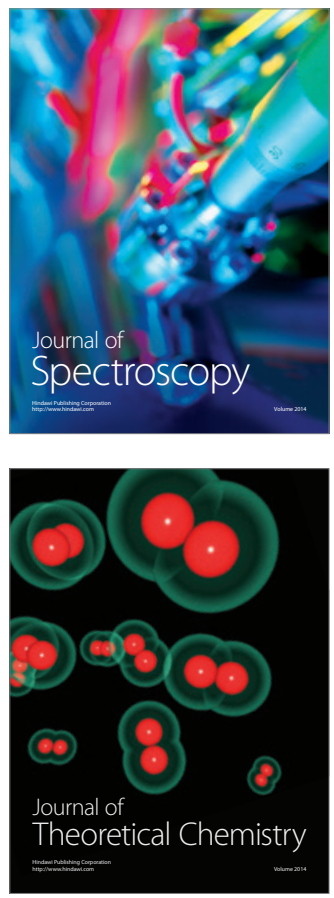
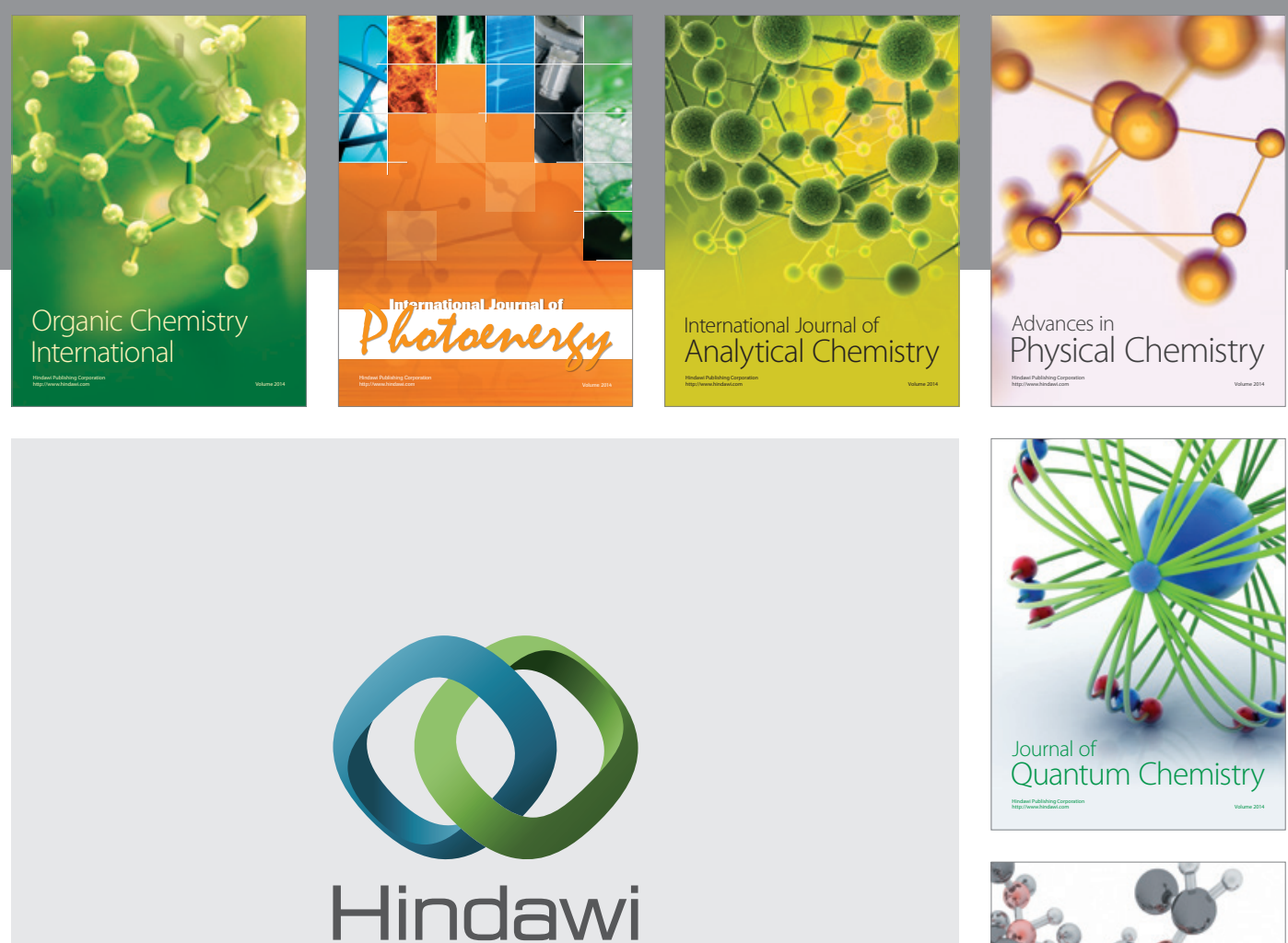

Submit your manuscripts at

http://www.hindawi.com

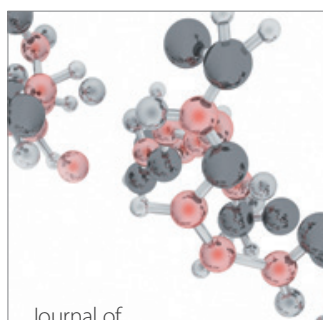

Analytical Methods

in Chemistry

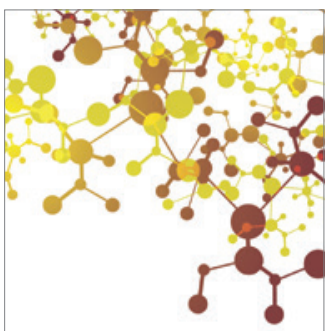

Journal of

Applied Chemistry

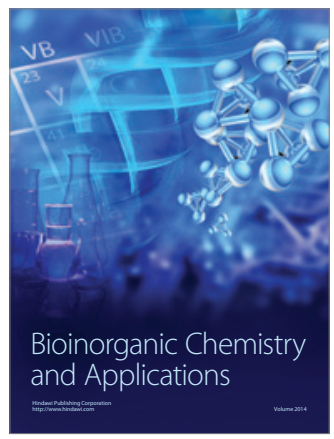

Inorganic Chemistry
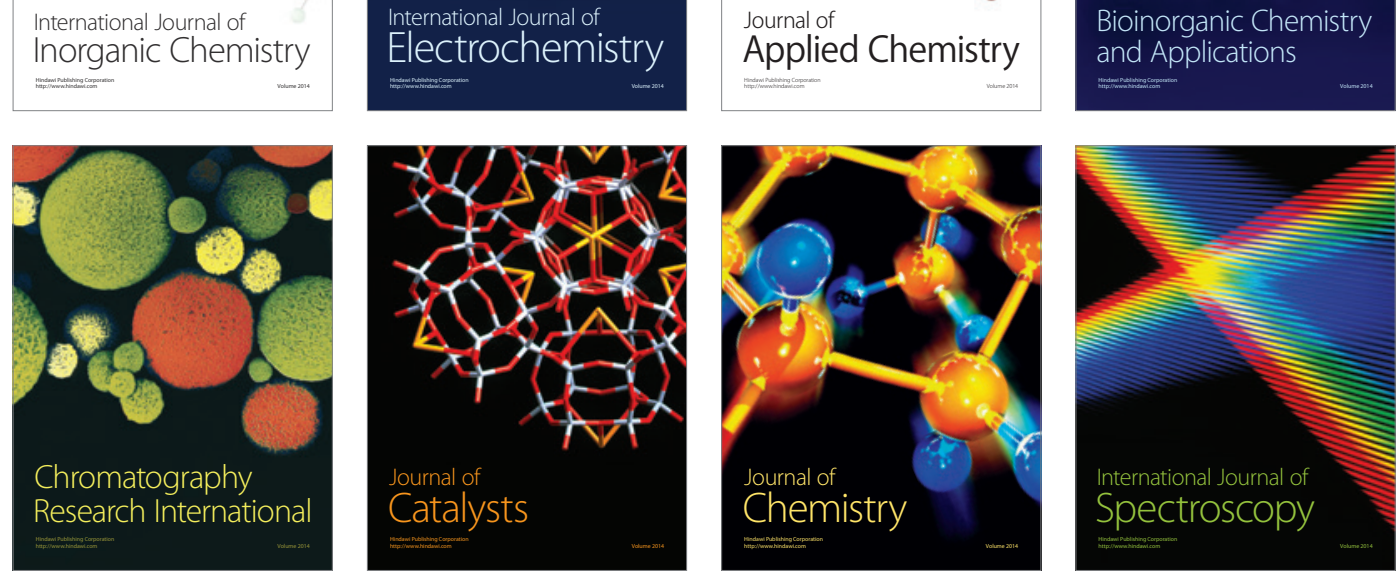